\title{
Results of research on the intensification of the process of cleaning potato tubers by ultrasonic action and their subsequent storage
}

\author{
$A$. Dorokhov ${ }^{1}, A$. Aksenov $^{1}, A$. Manokhina $^{2}$, and $M$. Mosyakov $^{2, *}$ \\ ${ }^{1}$ Federal Scientific Agroengineering Center VIM, 1st Institutskiy proezd, house 5, 109428, Moscow, \\ Russia \\ ${ }^{1}$ Russian State Agrarian University-Moscow Agricultural Academy named after K.A. Timiryazev, \\ Timiryazevskaya street, house 49, 127550, Moscow, Russia
}

\begin{abstract}
The data on the gross harvest of tubers in the Russian Federation are given: approximately $71 \%$ of potatoes are produced by the population, $17.4 \%$ by agricultural enterprises and $11.5 \%$ by farms. It is noted that in the industrial production of potatoes, negative impacts on the soil are associated with crushing and removal of the fertile soil layer, which arise in the process of extracting root crops by the digging and separating working bodies of the harvesting machines. It is proposed to use ultrasonic action on root crops for cleaning them from soil impurities. It was determined that in order to intensify the process of cleaning tubers by ultrasonic action during harvesting, it is necessary to provide operating and technological parameters (frequency of ultrasound oscillations $\mathrm{fl}=48$ $\mathrm{kHz}$, vibration intensity $\mathrm{S}=42 \mathrm{~W} / \mathrm{cm}^{2}$, exposure time $\mathrm{t}=90 \mathrm{~s}$ ) of ultrasonic equipment, which will ensure the completeness purification is not less than $84.7 \%$. The results of comparative studies on the intensification of the cleaning of potato tubers allow us to conclude that, regardless of the mass and type of pollution, the greatest positive effect of ultrasonic exposure is observed when processing tubers, the completeness of cleaning of which is on average $13-20 \%$ higher.
\end{abstract}

\section{Introduction}

The dynamics of gross collections of tubers such as potatoes shows that over the past decades, production volumes have been steadily increasing, then noticeably decreasing.

In 1990, agricultural enterprises accounted for $70 \%$ of total output of vegetables whereas private agricultural production accounted for 30\% of output, whereas by 2010 this situation was practically reversed. Today, $71 \%$ of all potatoes are produced by individuals while agricultural enterprises account for $17.4 \%$ of total yield. Besides that, private farms account for $11.5 \%$ of total yield.

An increase of industrial production by the agricultural industry would make it possible to ensure high quality of final products and the development of the sub-sector of the industry.

\footnotetext{
${ }^{*}$ Corresponding author: Maks.Mosyakov@yandex.ru
} 
It should be noted, however, that the level of mechanization of potatoes harvesting significantly lags far behind the level of mechanization of their cultivation [1-4].

Along with the soil factor that determines the quality of harvesting conditions, it is necessary to highlight a factor such as the agrophysical properties of potato tubers. The storage depends largely on their harvesting and post-harvest preparation for storage.

One of the crucial requirements to harvesting is the prevention of crop loss and the assurance of its high quality and low proportion of unmarketable products.

Post-harvest commodity processing of products consists of operations that are divided into basic, specific and auxiliary. The main operations include sorting and calibration of tuber crops that ensure consistent product quality.

Specific operations are performed for individual groups or types of products, which is due to the structural features, as well as the physiological state or the presence of defects. These include the separation of foreign impurities - soil, stones, plant residues, tops, weeds. Auxiliary operations are preparatory in nature and are intended to help the main ones delivery of products, containers and packaging materials to the place where the main operations are performed, packaging, labeling.

The auxiliary operations for post-harvest processing of potato tubers should also include cleaning from various mechanical impurities.

For their cleaning, dry cleaning machines are currently used by mechanical action on the processed material and washing machines that allow cleaning by immersing tubers in a loading bath filled with working fluid.

According to the principle of washing machines are divided into the following types: washing drum, conveyor washing machine, brush washing machine bunker type, brush washer, conveyor type, impeller washer [5-10].

The main design features of dry cleaning machines (brush and blade) include the sequential movement of the tuber from the highest to the lowest force by adjusting the speed of the cleaning brushes.

This fact is explained by an increased contamination of potato tubers at the place where they are fed for processing and a consistent decrease when moving along the working surface of the technological cleaning module.

Drum and conveyor washing machines are most widely used for industrial cleaning of tubers, which is due to a more gentle effect on the processed material, mainly due to the influence of the working fluid under a certain regulated pressure.

It is known that energy passed to a liquid is expended on cavitation processes that result in breakup of particles of materials. These processes are connected with each other [15].

On the one hand, for the destruction of soil particles, it is required to: create a high pressure in the liquid and ensure the presence of soil particles in the area of this high pressure [11-14].

On the other hand, the presence of a considerable number of soil particles in liquid, changing its properties, alters pressure when the same settings of an ultrasonic unit are used and thus affects the intensity of cavitation processes.

\section{Materials and methods}

To determine the impact of the technological parameters of ultrasonic action on the process of cleaning potato tubers from soil impurities and study the impact on the storage process, it is necessary to conduct research on the impact of technological parameters of ultrasonic action on the completeness of cleaning the pile and laying potatoes for storage.

To determine the effect of ultrasonic exposure on root crops in terms of cleansing them from soil impurities, certain studies were carried out using ultrasonic equipment (Fig. 1). The equipment comprised a UZG-2K generator designed for use together with 
piezoceramic radiator PI - 1.4 - 2.2 (ring type) and a submersion basin made of a radiationtransparent material. These components were arranged into an integrated ultrasonic equipment set.

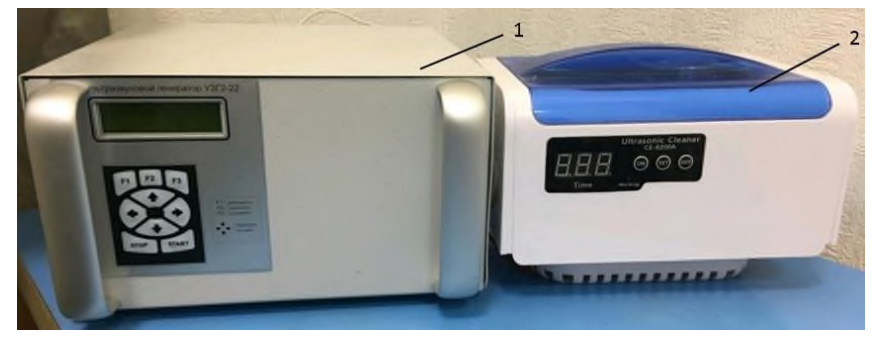

Fig. 1. Laboratory Setup for Studying Ultrasonic Effect on the Process of Cleansing Roots from Soil Impurities: 1 - ultrasound generator UZG-2K; 2 - ultrasound-transparent basin.

Following a prior ranging of the factors that have the defining affect on the process of potatoes cleaning, the most important of those were distinguished. These include: the oscillation frequency $f, \mathrm{kHz}$; the oscillation strength $\mathrm{S}, \mathrm{W} / \mathrm{cm}^{2}$; the exposure time $\mathrm{t}, \mathrm{s}$. 4]:

As an optimization criterion, the completeness $(v, \%)$ of tuber cleaning was chosen [2-

$$
v=\frac{m_{1}-m_{2}}{m_{1}} \cdot 100 \%
$$

where $\mathrm{m}_{1}$-is the mass of the potato tuber before ultrasonic exposure, $\mathrm{kg} ; \mathrm{m}_{2}-$ is the weight of the root/tuber after the exposure to ultrasound, $\mathrm{kg}$.

Soil clumps should be broken up in the work fluid, which should be kept at a constant temperature throughout the experiment. The results of the ultrasonic study demonstrated that ultrasonic devices operate at frequencies of $f=22,30,35,44$ and $130 \mathrm{kHz}$, and generate droplets of the size of 65 to 18 um [15].

With increase of ultrasound oscillation frequency the degree of breakdown of the cleaned product decreases.

When carrying out experiments to determine the optimal regime and process parameters of ultrasonic exposure, a synchronous mode of operation of the generator and the transformer must be ensured.

The method of study of the effect of ultrasonic exposure on the process of potatoe tuber cleansing from soil impurities is as follows.

Experiments to determine the effect of ultrasonic exposure on the process of root crop cleaning were carried out on the Red Scarlet potato variety.

Following that, the studied root tubers were weighed at M-ER 122ACFJR-300.01 LCD scales.

Following that, a layer of soil of specific weight was applied on the surface of the studied tubers in accordance with the plan of experiment and the soil layer was concurrently moistened.

The studies were carried out using light (in terms of physical and mechanical properties) soils - sandy soils, as well as using heavy soils - loamy soils.

Following the application of a layer of soil onto the studied tuber, it was dried under natural conditions with ambient air temperature $\mathrm{T}=20-25^{\circ} \mathrm{C}$, to the point of drying of the soil crust. This was determined by visual observation. The specimen was subsequently weighted again. 
When carrying out studies to determine the optimal parameters of ultrasonic exposure during potato tuber cleansing, studied tubers were covered with heavy loamy soils having the weight $\mathrm{m}=150 \mathrm{~g}$.

Following the completion of operations needed to prepare the potato tuber to ultrasonic treatment, the ultrasonic basin was filled with working liquid, the tuber root 1 on the stand 2 was lowered into the working volume of the basin, and the device was switched on.

In order to determine the effect of process parameters of ultrasonic exposure on the process of cleansing potato tubers of soil impurities, it was necessary to conduct trial experiments that would reveal the effect of process parameters of ultrasonic exposure on root crop cleanliness.

\section{Results and discussion}

The results of studies to determine the dependence of the completeness of cleaning of vpotato tubers on the mass of soil impurities applied to tubers and the time of tultrasonic exposure were recorded in the observation log and are presented in tables 1 and 2.

Table 1. The results of studies to determine the effect of the studied factors on the degree of cleanliness of potato tubers (sandy soils).

\begin{tabular}{|c|c|c|c|c|c|}
\hline \multirow{2}{*}{$\begin{array}{c}\text { Exposure Time } \\
\mathrm{t}, \mathrm{s}\left(\mathrm{f}_{1}=48.0 \mathrm{kHz}, \mathrm{S}=42\right. \\
\left.\mathrm{W} / \mathrm{cm}^{2}\right)\end{array}$} & \multicolumn{5}{|c|}{ Tested Factor } \\
\cline { 2 - 6 } & \multicolumn{5}{|c|}{ Weight of Soil Impurities $\mathrm{m}, \mathrm{g}$} \\
\cline { 2 - 6 } & 50 & 100 & 150 & 200 & 250 \\
\hline 90 & 97.4 & 96.6 & 96.1 & 95.8 & 94.7 \\
\hline 180 & 98.6 & 98.1 & 97.7 & 97.1 & 96.8 \\
\hline 280 & 98.9 & 98.8 & 98.3 & 98.1 & 97.3 \\
\hline 380 & 99.6 & 99.4 & 99.1 & 98.2 & 98.4 \\
\hline 480 & 99.8 & 99.6 & 99.4 & 99.4 & 99.2 \\
\hline
\end{tabular}

The data shown in Tables 1 to 2 demonstrate that the best results when cleaning tuber crops from soil impurities by exposure to ultrasound are achieved by increasing the intensity of oscillations $(S)$ and exposure time (t) within the range of studied values, regardless of oscillation frequency $\left(\mathrm{f}_{1}\right)$ alterations of the ultrasound.

Table 2. The results of studies to determine the effect of the studied factors on the degree of cleanliness of potato tubers (loamy soils).

\begin{tabular}{|c|c|c|c|c|c|}
\hline \multirow{2}{*}{$\begin{array}{c}\text { Exposure Time } \\
\mathrm{t}, \mathrm{s}\left(\mathrm{f}_{1}=48.0 \mathrm{kHz},\right. \\
\left.\mathrm{S}=42 \mathrm{~W} / \mathrm{cm}^{2}\right)\end{array}$} & \multicolumn{5}{|c|}{ Tested Factor } \\
\cline { 2 - 6 } & 50 & 100 & 150 & 200 & 250 \\
\cline { 2 - 6 } & 83.6 & 80.9 & 77.6 & 73.2 & 72.1 \\
\hline 90 & 84.8 & 82.3 & 79.8 & 76.4 & 74.5 \\
\hline 180 & 86.4 & 84.3 & 82.7 & 80.4 & 78.5 \\
\hline 280 & 87.8 & 86.3 & 84.4 & 83.4 & 81.8 \\
\hline 380 & 88.3 & 87.7 & 85.5 & 84.2 & 82.1 \\
\hline 480 & & \multicolumn{5}{|c|}{} \\
\hline
\end{tabular}

The data received during the conducted studies were processed using a PC and are presented in the form of graphs in Figures 2 through 3 . These most accurately reflect the prospects of future studies of the effects of ultrasonic treatment on the process of cleaning potato tubers to ensure the highest quality of separation. 
The minimal exposure time applied to light soils and the studied potato tuber of less than 90 seconds results in the minimum degree of cleanliness, $94.7 \%$ with the oil impurities quantity of 250 grams.

The maximum degree of cleanliness of potato tubers $v=99,8 \%$ is achieved with ultrasonic exposure duration of $480 \mathrm{~s}$. This is explained by the increased time of exposure of the root to the work liquid.

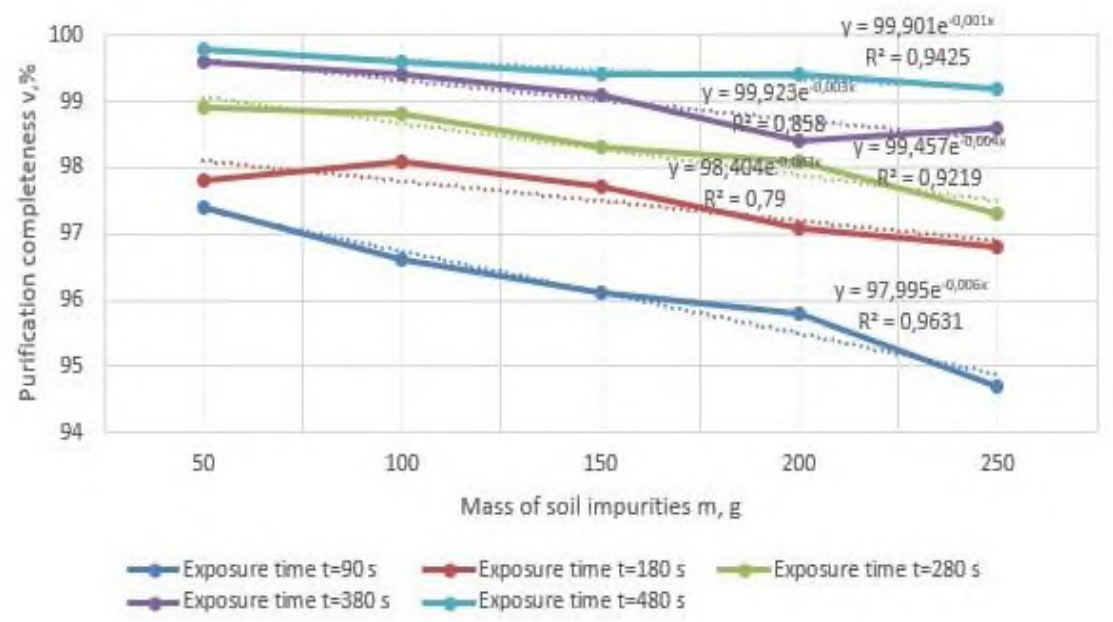

Fig. 2. The Results of the Study to Determine the Effect of Ultrasonic Exposure Time $t$ on the Cleanliness of Potato Tubers with $\mathrm{f}_{1}=48.0 \mathrm{kHz}, \mathrm{S}=42 \mathrm{~W} / \mathrm{cm}^{2}$ (sandy soils).

Within the same time interval of ultrasonic exposure, alteration of the degree of cleanliness of potato tubers depending on the increase of the amount of soil impurities declines by $1.3 \%$.

An opposite trend is observed when cleaning potato tubers from heavy soils. For example, the degree of cleanliness of the tuber with the minimum exposure time $t=$ of $90 \mathrm{~s}$ and the weight of soil impurities $m=50 \mathrm{~g}$, equals to $v=87.6 \%$. This is $9.8 \%$ lower than the same indicator obtained under a comparable degree of contamination of a tuber with sandy soil and ultrasonic exposure time.

Maximum duration of ultrasonic exposure $t=$ of $480 \mathrm{~s}$ with the minimum weight of soil contaminating the tuber $\mathrm{m}=50 \mathrm{~g}$ and the maximum $\mathrm{m}=250 \mathrm{~g}$ allows for the degree of cleanliness $v=$ of $94.3 \%$ and $82.1 \%$, respectively, which is $5.5 \%$ and $17.1 \%$ lower than the qualitative values of root cleanliness degree with sandy impurities.

When the ultrasonic exposure time increases within a constant value of contamination of potato tubers with soil impurities, the completeness of cleaning increases: at $\mathrm{m}=50 \mathrm{~g}$ by $7.6 \%$; at $\mathrm{m}=100 \mathrm{~g}$ by $1.9 \%$; at $\mathrm{m}=150 \mathrm{~g}$ by $2.1 \%$; at $\mathrm{m}=200 \mathrm{~g}$ by $1.8 \%$; at $\mathrm{m}=250 \mathrm{~g}$ by $2.3 \%$ (Fig. 4).

The increase of time of ultrasonic exposure would impair the feed rate consistency of the processes heap and affect the continuity of the harvesting process.

Consequently, in order to intensify the process of cleaning tuber crops by exposure to ultrasound on sandy soils an to intensify their post-harvest processing, certain process parameters of ultrasonic equipment should be provided (ultrasound oscillation frequency $f_{1}=48 \mathrm{kHz}$, oscillation intensity $S=42 \mathrm{~W} / \mathrm{cm}^{2}$, exposure time $t=90 \mathrm{~s}$ ) that should make it possible to achieve the degree of cleanliness of no less than $84.7 \%$. 


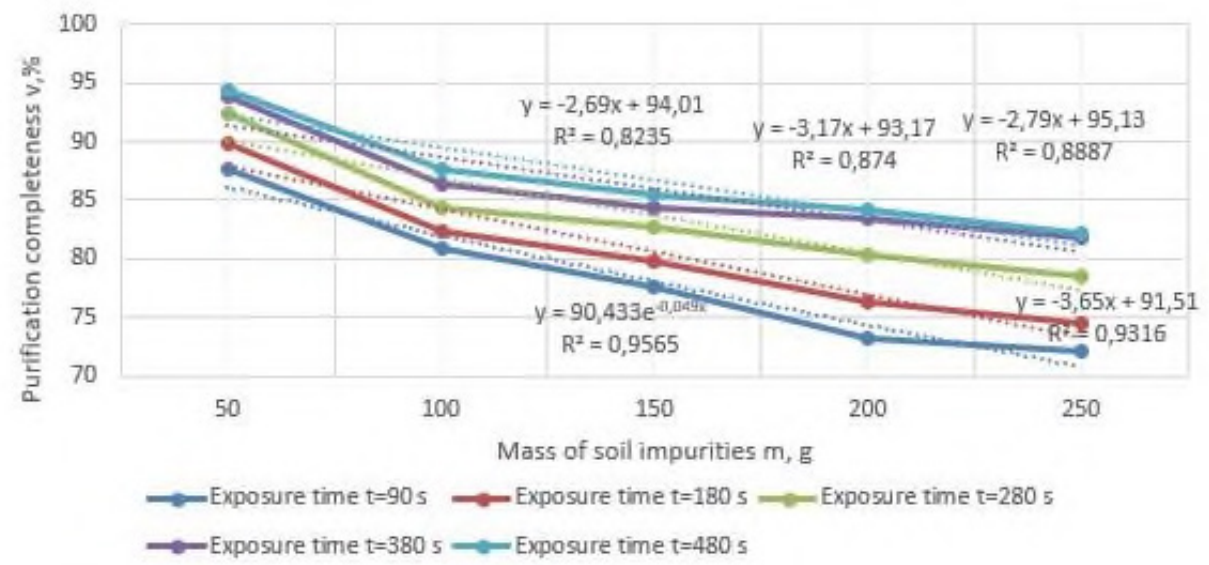

Fig. 3. The results of the study to determine the effect of ultrasonic exposure time $t$ on the cleanliness of potato tubers with $\mathrm{f}_{1}=48.0 \mathrm{khz}, \mathrm{s}=42 \mathrm{w} / \mathrm{cm}^{2}$ (loamy soils).

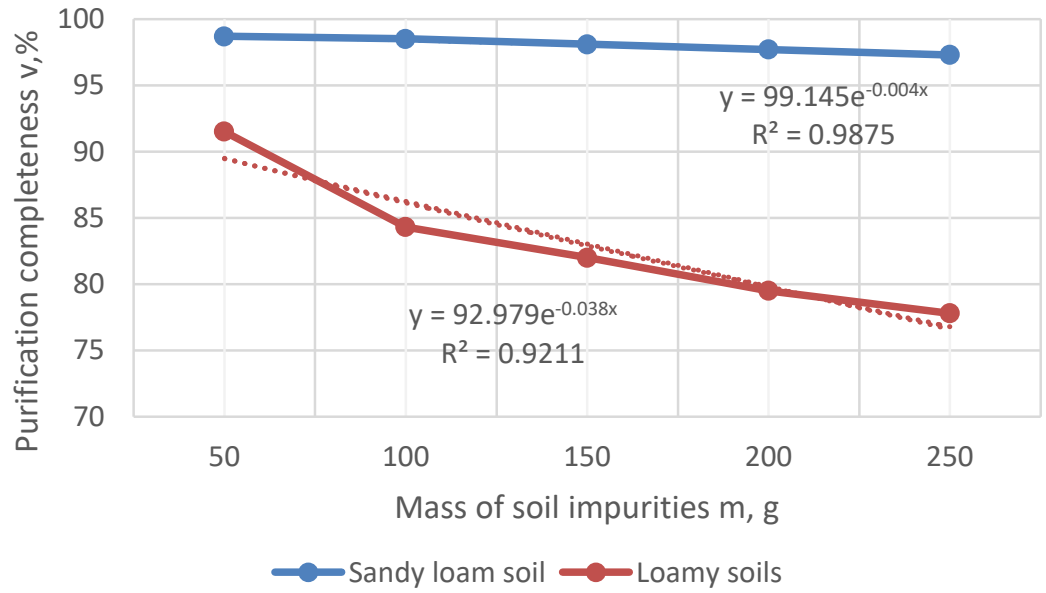

Fig. 4. The results of comparative studies to determine the effect of ultrasonic exposure time t on the cleanliness of potato tubers with $\mathrm{f}_{1}=48.0 \mathrm{khz}, \mathrm{s}=42 \mathrm{w} / \mathrm{cm}^{2}$ depending on the grain sizes of impurities.

To sum the above information up, the analysis of the results of comparative studies on the intensification of cleaning potatoe tubers from impurities of various weight and grain sizes allows to make the conclusion that, regardless of the weight and type of impurities, the highest beneficial effect of ultrasonic exposure was noted when processing potatoe tubers. On the average, the degree of cleanliness of this root crop was 13 to $20 \%$ higher. This is corroborated by the diagram shown in Figure 5. 


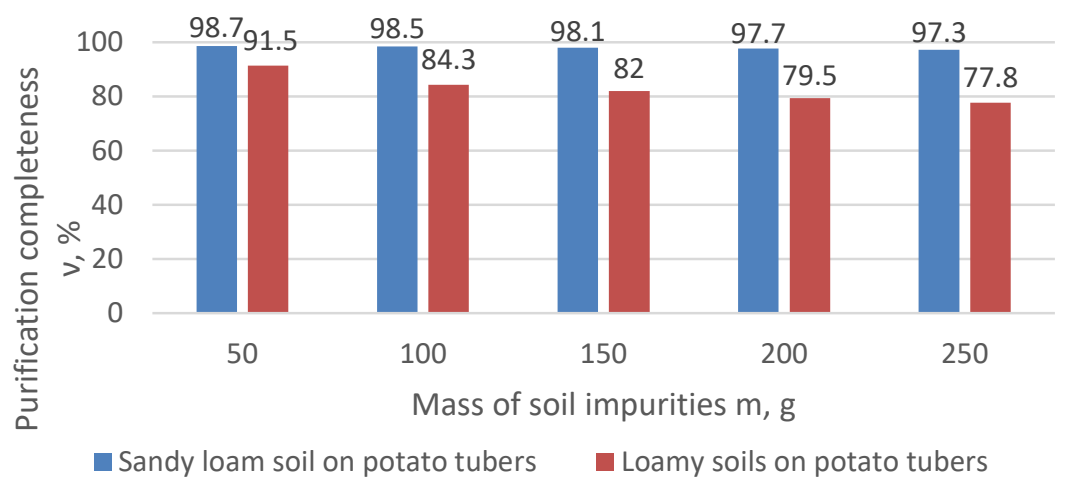

Fig. 5. The Results of Comparative Studies to Determine the Effect of Ultrasonic Exposure Time on the Cleanliness of Potato Tubers with $\mathrm{f}_{1}=48.0 \mathrm{kHz}, \mathrm{S}=42 \mathrm{~W} / \mathrm{cm}^{2}$ Depending on the Grain Sizes of Impurities.

\section{Conclusion}

After the technological operation of cleaning tubers from mechanical impurities with the intensification of ultrasonic action, they were dried under natural conditions and then stored.

Storage modes of the ultrasound-treated tubers was determined by the normative document as a guideline for the storage of fresh potatoes and vegetables, Order MT USSR No. 64 dated April 10, 1974, NTP - APK 1.10.12.001-02 «Norms of technological design of enterprises for storage and processing of potatoes, fruits and vegetables» and recommendations for storage of vegetables developed by the Research Institute of vegetable growing based on years of research results and industrial practice.

After harvesting, the tubers are subjected to commodity processing, the main purpose of which is to form product batches of uniform quality by dividing them into quality gradations in accordance with the requirements of regulatory documentation.

Consequently, studies of the processes of interaction and cohesion of soil particles with the surface of tuber crops during the exposure to ultrasound is a line of theoretical and experimental research presenting immediate interest.

This article was produced with the financial support of Russian State Agrarian University - Moscow Timiryazev Agricultural Academy, project topic: Substantiation of parameters of ultrasonic treatment on the intensification of potato tuber cleansing from soil impurities, and studies of its effects on storage processes, No. 1.1.5

\section{References}

1. Ablikov V. A., Scientific journal Cube GAU 121(07), 25-30 (2016)

2. Sibirev A. V., Aksenov A. G., Mosyakov M. A., Engineering technologies and systems 29, 1, 91-107 (2019)

3. Kalinin A. B., Teplinsky I. Z. and Kudryavtsev P. P., Potatoes and vegetables 2, 35-36 (2016)

4. Kukharev O. N., Larushin N. P., Research Journal of Pharmaceutical, Biological and Chemical Sciences 9, 3, 30-33 (2018) 
5. Laryushin N. P., Kukharev O. N. and Kiryukhina T. A., Science in Central Russia 6(18), 48-58 (2015)

6. Zykin E. S., Kurdyumov V. I., Bulletin of the Ulyanovsk State Agricultural Academy 1(37), 160-166 (2017)

7. Li S. T., Chen X. B., Chen W., Zhu S. P., Li Y. W. and Yang L., Journal of Cleaner Production 179, 55-61 (2018)

8. Sibirev A. V., Aksenov A. G. and Mosyakov M. A. Journal of Engineering and Applied Sciences 23, 10086-10091 (2018)

9. N. Al-Dosary, N. Mordi, CIGR Journal 18(2), 32-42 (2016)

10. B. R. Amol, D. Sh. Pavan, B. P. Sumit and K. S. Keshav, International Journal of Mechanical Engineering and Technology 5, 180-186 (2014)

11. Luzgin V. I., Shestovskikh A. E. and Kandalintsev B. A., Efficient and high-quality supply and use of electricity: collection of proceedings of the 3rd International Scientific and Practical Conference 101-105 (2014)

12. Negrov D. A., Eremin E. N., Novikov A. A. and Shetel L. A., Ultrasonic oscillatory systems for the synthesis of polymer composite materials Om GTU (2012)

13. Sibiryov A. V., Aksenov A. G., Research and Publishing Center "Relevance. RF " 9799 (2019)

14. Dorokhov A. S., Aksenov A.G. and Sibiryev A. V., Bulletin of the Ulyanovsk State Agricultural Academy 2(46), 6-13 (2019)

15. Kalinin A. B., Smelik V. A., Teplinsky I. Z. and Pervukhina O. N., Selection and substantiation of the parameters of an agroecosystem ecological state for monitoring technological processes of crop cultivation 39, 315-319 (2015) 